\title{
"Otherness" as Threat: Social and Educational Exclusion of Roma People in Greece
}

\author{
Christos Parthenis \\ University of Athens \\ Greece \\ George Fragoulis \\ University of Athens \\ Greece
}

ABSTRACT: This paper focuses on aspects of the social and educational exclusion that Roma people face in the Greek context. It argues that diversity has been constructed as a threat for the security, the social cohesion, and the well-being of western societies. Drawing from two case studies of primary schools conducted in a highly deprived suburb of Athens, where most Roma live in harsh conditions, we argue that socially constructed dispositions regarding diversity and inadequate state policies are major obstacles for the improvement of educational opportunities and life chances of Roma people in Greece.

KEYWORDS: Roma, diversity, exclusion, Greece, policy

\author{
Diversity as Threat in a Fluid World \\ Diversity in Education \\ The Continuum of Roma Exclusion \\ Research Design \\ Results \\ Conclusion \\ References \\ Author Contact
}

Globalization and immigration constantly change the demography of nation-states and transform most western societies into multicultural societies. The unity between the nation-state and the national society is dismantled, and new forms of authority and competitiveness are created (Beck, 1999). The production of values and meanings is no longer subject to local restrictions (Bauman, 2004). States are increasingly involved in a local, global, and multilevel system of governance that is difficult to monitor and control. The range of 
strategic options available to national governments has been reduced, and states seem increasingly unable to determine their own fate (Held \& McGrew, 2004).

\section{Diversity as Threat in a Fluid World}

Today, cultures have come closer to one another with the aid of technology. As a result of the technological explosion, largely in the domain of transportation and information, people have entered into an altogether new condition of neighborliness, even with those most distant. However, the theorization of this new world as a global village overestimates the communitarian implications of the new media order (Appadurai, 2005). The increased awareness of the variety of lifestyles and values could lead to mutual understanding; however, the acknowledgement of the "other" does not always lead to acceptance (Held \& McGrew, 2004). In a fluid world, those characterised as "different" often find themselves in a precarious position. Globalization creates new forms of global, supranational organizations or communities that connect people across national borders, but simultaneously it divides communities within and outside the traditional nation-state boundaries. Ethnic and racial differences often become accentuated when the "others" come closer (McGrew, 2003). According to Bauman (1997), the arrival of "foreigners" has an impact equal to that of an earthquake, as the newcomer destroys the stability and the secure environment of everyday life and questions the assumptions of the dominant group. The severity of the problem appears to depend only on the degree of the foreigners' "adaptation" to the values of the host country (Sayad, 2004).

Currently, Europe faces again a surge of immigrants and refugees from the Middle East and Africa. Multiculturalism is increasingly viewed as a threat to the cohesion, the security, and the welfare system of European societies. In the literature on anti-immigrant attitudes, two broad explanations are offered: one is rooted in perceptions of economic threat or economic burden, and the other in perceptions of cultural threat (Kymlicka, 2015). After the terrorist attacks in the United States in 2001, known as 9-11, and in major European cities the following years, Muslim immigrants were viewed as a threat to national security. Roma, on the other hand, are viewed as a "local" threat to the safety and quality of life and education of the dominant groups in every neighborhood (Markou, 2013). This is hardly a new situation, as the "threat" of multiculturalism to social cohesion has long been a key topic of the Right (May, 2009). Although diversity in terms of race, ethnicity, sexuality or physical ability has been always a source of exclusion, recently we are witnessing the diffusion of discriminatory perceptions into a significant part of the European societies, in the form of the rise of a public discourse against multiculturalism and the empowerment of xenophobic political parties (Parthenis \& Fragoulis, 2016; Vertovec \& Wessendorf, 2010). 


\section{Diversity in Education}

Since World War II, many immigrants have settled in the United Kingdom and in other European states, such as France, the Netherlands, Germany, Sweden, and Switzerland. Many Southern and Eastern European immigrants have settled in Western and Northern European nations in search of better life chances. Ethnic and immigrant populations have also increased significantly in Australia and Canada in the same period (Banks, 2010). The presence of these "others" in the schools of the host countries has provoked great controversy. The assimilation model was dominant until the 1960s. "Others" were viewed as bearers of an inferior and defective identity that should be "rectified" through education (Govaris, 2004; Markou, 2010). The integration model arose as a response to the criticism against assimilation, acknowledging diversity, yet at the same time ensuring the superiority of the dominant culture (Govaris, 2004; Markou, 2010).

The 1960s was the time for the celebration of difference, particularly in the United States. Oppressed groups, such as African-Americans, women, disabled people, or homosexuals, claimed their right to be different and sought public recognition for their collectivity. In Europe, multiculturalism has a narrower focus than in countries that have been built up out of immigration, such as the United States or Canada (Modood, 2013). However, the new multicultural discourse has commonly challenged the nationalistic orientation of the traditional Western education. Multicultural education is a reform movement that seeks to promote equal opportunities for all children and to reduce prejudice and discrimination against oppressed groups. It is not limited to curricular changes; it involves changes in the total school system (Banks, 2010). Some multicultural educators recommend a critical approach to cultures of domination, called critical or emancipatory pedagogy. Multicultural education has a challenge to be counterhegemonic. When issues such as racism, class privilege, and sexism are left silent in the classroom, the implicit message for students is that the school does not acknowledge that experiences of oppression exist (Erickson, 2010).

In the 1990s, multiculturalism was in the ascendant. The notion of a pluralized public sphere, where cultural, linguistic, and religious diversity could be positively accommodated, was becoming an increasingly accepted part of social and political life. However, after the terrorist attacks of 2011 in the United States and the following years in Europe, the threat of multiculturalism has been reaffirmed among the sceptics on multiculturalism as a proof of the inability of the "others" to accept dominant societal mores and values (May, 2009). Modood (2013) argued the fact that most terrorists were born and brought up in the West offered the sceptics arguments on the fallacies of multiculturalism. The role of education has often been seen at the centre of these attacks (May, 2009). Intercultural education was promoted as a solution to the problems created in the 
multicultural western societies. However, as Coulby (2011) pointed out, what matters is not how the education policy is named, but what its actual content represents. The analysis of educational policy formulation in highly diverse areas requires more than exhortation about what should be done. This paper explores aspects of Roma educational exclusion in Greece as an example of an inadequate multicultural education policy.

\section{The Continuum of Roma Exclusion}

Roma are a heterogeneous minority people dispersed across the world with no historical homeland. Everywhere they resided, they were persecuted and faced with discrimination (McGarry, 2010; Widmann, 2007). They arrived in Europe in the $13^{\text {th }}$ century, most possibly coming from India. The myths and the stereotypes accompanying Roma have led to mistrust on the part of the Europeans (McGarry, 2010). Their presence in territories that later became part of the Greek state dates back to the $14^{\text {th }}$ century (Terzopoulou \& Georgiou, 1998). The Christian myth about the demonic nature of Roma that conduced to the crucifixion of Christ is dominant in the Greek tradition, while they were also considered collaborators of the Ottoman Empire (Troumbeta, 2008). These stereotypical images strengthened the negative collective representation of the Roma in Greece and elsewhere. Under the Nazi regime, the Roma faced the ethnic cleansing practices of the National Socialist Germany (Lewy, 2000).

Nowadays, the Roma population is estimated between 10-12 million located mainly in Central and Eastern Europe, with most living in poverty and residential isolation. The European Commission (2004) stresses the inadequacies of the member states' policies regarding education, employment, housing, and healthcare of the Roma. The Council of the European Union (2009) described the living conditions of Roma as "a human tragedy," stating simultaneously that far-reaching exclusion entails social instability and represents a problem in economic terms. However, the European Union (EU) exerted pressure mainly on the post-communist countries to improve the treatment of the Roma while being concerned about preventing a massive movement of Roma from Eastern to Western Europe in search for better living conditions (Kymlicka, 2007).

In Greece, the Roma population is reported to be at least 150,000 (Moraitou, 2013), although the European Commission against Racism and Intolerance (ECRI, 2015) raised this number to 265,000. Greece has experienced radical changes over the last 25 years, becoming the main gate of the migration streams towards Europe. Act 2413/1996 introduced intercultural education in Greece, despite its inadequacies in promoting an intercultural culture (Markou, 2010). Access to the education system and the provisions of the welfare state for the Roma has always been limited. They were granted civil 
rights in the 1970s; nevertheless, they remained marginalized (Markou, 2013). The state never implemented a consistent policy regarding the Roma or other diverse groups. Over the last 20 years, university programs co-funded by the Greek state and primarily the EU have played a central role in the education of ethno-culturally diverse groups, often in hard conditions and without adequate support by the state apparatus.

The Roma are still faced with discrimination and are subject to bio-politics for the protection of the "normal" population. Foucault $(1978,1986)$ sheds light on the diffuse technologies of power that produce divisions between the self and the "other" (sane-insane, healthy-disabled, lawful-criminal, etc.) and construct deviant groups that have to be regulated. The normalizing society is a historical outcome of technologies of power centered on life. Power establishes its domination over life in two forms. The first form centers on the body as a machine, aiming at the optimization of its capabilities, the extortion of its forces, and the increase of its docility. The second constitutes the bio-politics of the population, aiming at the regulation of the conditions related to issues such as birthrate, health, life expectancy, housing, or migration. Power and knowledge arise as an agent of the transformation of human life. Gradually, there was an explosion of numerous techniques for achieving the subjugation of bodies and the control of populations, marking the era of bio-power. Bio-power also acted as a factor of segregation and social hierarchization, ensuring relations of domination. Western people started to learn what it meant to have a body, conditions of existence, probabilities of life, and individual and collective welfare (Foucault, 1978). Thus, human beings are gradually transformed into subjects through processes of recognition and domination on the self. Foucault analyzes the practices of the "care of the self," emphasizing the importance of an intensification of the relation to oneself by which one constitutes oneself as the subject of one's acts. Practices of the self are not self-invented but are based on norms that already exist in a given socio-political and cultural context (Foucault, 1986).

ECRI reports on Greece $(2000,2005,2009,2015)$ offer a detailed description of bio-politics regarding the Roma population. In 2000, the ECRI reported that the Roma were vulnerable to discrimination in various areas of public life. Inadequate educational possibilities resulted in widespread illiteracy within their population. Some municipal authorities expelled the Roma from the camps they lived in, often without providing alternative accommodation. This has resulted in their being repeatedly expelled from each new place they attempt to settle. These expulsions are sometimes accompanied by humiliating and discriminatory treatment by local authorities and the police. ECRI reports emphasize that the implementation of plans for improving the life chances of Roma often encountered local resistance. Moreover, Roma people were excluded from citizenship rights and benefits, and their integration in the social security system was low. Although indigenous Roma are entitled to free health care, most of them are not aware of their rights. In all the subsequent reports on 
Greece, the ECRI $(2004,2009)$ states that the Roma still face discrimination in respect of housing, employment, education, and access to public services. It stresses again the importance of overcoming local resistance to initiatives that benefit Roma and notes that the European Court of Human Rights has condemned Greece for the violation of Roma rights. In its last report, the ECRI (2015) maintains that the Integration Action Plan for Roma (2003-2008) in the areas of education, employment, health, and housing, which was funded by the EU, has largely failed. As Markou notes (2013), most Roma still live in settlements outside the residential zones, without legal access to running water or electricity. Even when they live inside the residential zones, they live in ghettos, isolated from the socio-cultural and economic life of the region.

Stereotypical perceptions about the Roma have been constructed over a long period and are reproduced through state policies and everyday practice of the dominant groups, including the school community. Teachers are products of an education system that produces "good" and "bad" students, thereby incorporating and legitimizing early in their school life the belief that some students are condemned to fail. School fulfils its reproductive role by exercising symbolic violence, building on the power of socially constructed beliefs that social subjects do not question. Symbolic violence rests on the socialization process that provides subjects with the necessary perceptive schemes in order to perceive and obey the injunctions inscribed in a situation (Bourdieu, 2000). According to Bourdieu (1990), habitus produces individual and collective practices in accordance with the schemes generated by history. This system of dispositions governs practice. People do not feel the influence of their past selves and do not recognize the legitimate demands of their dispositions because they are deeply rooted within them. We argue that these stereotypical perceptions about the Roma constitute a major obstacle for establishing those conditions that will allow people to improve their life chances and freely construct their identity.

\section{Research Design}

The aim of this paper is to explore the factors related to high dropout rates and irregular school attendance of Roma children in Greece. We present the results of dual case studies conducted in the first trimester of 2013 in two primary schools located in a highly deprived area in the western suburbs of Athens. We use the pseudonym "City" for this area.

The research project was part of a university Programme for Roma Education in the period 2010-2015. Indicatively, the scientific committee organized school enrolment for children, adult enrolment in Adult Education Centres and Second Chance Schools, reception classes, summer schools, inservice training for teachers, and various actions for bridging the communication 
gap among the Roma, the school, and the local community. Simultaneously, a number of research projects were conducted in order to understand the deeper causes of persistent Roma exclusion and thus intervene more effectively. In this paper, we present the specific case studies as typical examples of the difficulties and the resistance encountered in removing social and educational barriers. Specifically, we explore the following topics:

1. Teachers' and principals' perceptions of the reasons for the high dropout rates of Roma children; teachers' and principals' practices for removing the barriers that Roma children face.

2. Roma parents' and students' perceptions of the importance of school education and the reasons for the high dropout rates of Roma children, as well as the relations they have with the teaching staff and non-Roma parents and students.

3. The perceptions of Roma mediators and the coordinator of the "City" of the reasons for the high dropout rates of Roma children.

\section{Participants}

Participants were drawn from two primary schools located in the City where approximately 3,500 Roma live in great poverty, most of them in camps on the borders or outside the residential zone. In school A, Roma students were the majority, while in school B only 14 out of approximately 200 students were Roma. The overall area has one of the highest dropout rates in Greece: in 2011 only $10 \%$ of school-age Roma children attended school regularly.

Participants were selected by using purposive sampling (Cohen, Manion, \& Morrison, 2005). The sample consisted of 23 participants: (a) the principals and the Roma mediators of both schools; (b) two teachers, eight students, and two parents from school A; (c) four students and two parents/legal guardians from school B; and (d) the coordinator of the "City," who was responsible for monitoring the implementation of the Programme. Both principals were experienced in directing schools with highly diverse student population. The first teacher was less experienced than the second one in working with Roma students. We note that the teaching staff of school B stated that they would prefer to be interviewed at the end of the Programme, thus partly overturning the research plan. Students were aged from 8 to 12. Parents/legal guardians had attended some grades of primary education, or had no formal schooling. The mediator of school A was 32 years old and graduated from primary education, while the mediator of school B was 19 years old and graduated from lower secondary education. Both mediators received training before taking up their duties. 


\section{Data Collection and Analysis}

Twenty-three semi-structured interviews were conducted in total. Participants were informed about the purposes of the research, the anonymity of the records, and the possibility of being provided with a copy of the findings (Neuman, 2014). The consent and the presence of parents during the interviews with their children, as well as the consent of the children, were sought. No tape recorder was used according to the will of most participants; it seems that much more work needs to be done in order to build trust relationships. Thus, two researchers conducted the interviews by keeping notes.

The interview schedule included various questions in order to cover the topics of the research. The interviewers could modify the sequence of questions, change the wording, explain or add to them. Prompts and probes were also used. The response mode was unstructured, allowing the participants to express freely how they regarded situations from their own point of view (Cohen et al., 2005). Interviews with principals and teachers were conducted in their schools and lasted from 30 to 45 minutes. Interviews with the coordinator and the mediators were conducted in a coffee shop and lasted approximately 30 minutes. Finally, interviews with parents and students were conducted in their homes. Interviews with parents lasted from 25 to 40 minutes, while interviews with children lasted from 15 to 25 minutes.

The focus was not only on the content of the verbal material produced by the participants, but also on the latent meanings (Mayring, 2004). Data, referring to the translated responses to interview questions, were coded with specific categories for the purposes of the analysis. Categories were pre-determined, but the emergence of new categories was allowed. Content analysis was applied in order to develop interpretations and make meaning of the data (Cohen et al, 2005).

\section{Results}

Data analysis is presented according to four major categories explored in this paper: (a) perceptions of the reasons for Roma high dropout rates; (b) school practices for empowering Roma students; (c) Roma perceptions of the importance of school education; and (d) Roma relations with the non-Roma members of the school community. In addition, the perspectives of the Roma mediators and program coordinator from the unique "in-between" position are offered in comparison with other participants. 


\section{The High Dropout Rates of Roma Children}

The principal's role is very important for the management of multicultural schools and the development of actions to combat racism (Gillborn, 1995; Ryan, 2003). Principals and teachers of both schools cooperated eagerly with the people in charge of the implementation of the Programme. However, the interviews revealed a strong social determinism, bringing to the fore their deeply rooted belief that there is no hope for children that do not fit in with the dominant norms. These perceptions originate from teachers' socially constructed dispositions towards diversity (see also Kontogiannopoulou-Polydorides \& Fragoulis, 2009). Roma children are doomed to fail, because of their lifestyle and their contempt for school education.

In school $A$, the principal interpreted the school failure of Roma by listing their differences from the "normal" population:

Marriage, relocations, the people they mix with, their profession... school is not a priority...they stay out late, they don't wake up in the morning...they come from a poor socio-economic environment, they have poor stimuli...they have different habits.

The principal added that most Roma parents "do not participate in the parents' committees of the school...they are afraid to bear responsibility."

Teachers also argued that Roma are responsible for their fate. The first teacher stated:

Roma keep some children home to look after their younger siblings...they do not encourage them to attend school...children work with their parents...they do not have the basics...their progress is very slow...they lag behind because they do not have family support.

The second teacher stated that "Roma children are not interested in school...some of them work...they often relocate...one girl got married...they are indifferent towards schooling...they revel and sleep late." Once again, the school seems reluctant to assume responsibility for the education of all children. School demands from all parents a specific code of behavior, without taking into account their socio-cultural characteristics. This stance is another mechanism that contributes to the reproduction of the educational disadvantage of specific groups (Lareau, 2003).

Most students in school A argued that Roma children are partly responsible for their high dropout rates, because "they are lazy and indifferent...they wake up late...they find school boring." One student argued that parents must exert verbal and physical abuse on their children in order to make them attend school. Simultaneously, students asked their teachers to take action and explain to the Roma children the importance of schooling. However, three 
students also stressed the teachers' negative role, arguing that they marginalize Roma children. Notably, three additional students stated that Roma parents are also responsible: "They do not encourage their children to attend school...they keep them home to take care of the younger children."

As far as the parents are concerned, the first participant was the father of four sampled students. He attended school until the second grade; he is a peddler and often relocates. He attributed the high dropout rates of Roma to the inadequacies of the welfare state, but, most impressively, he argued for the abolition of the state allowance given to Roma in order to enroll their children in school: "There should be no relation between money and schooling." The second participant was the mother of two sampled students and the aunt of the last two sampled students from school A. She attended school until the fourth grade and she runs a family business. She argued that teachers are responsible for the high dropout rates of Roma: "They are racist...children freely decide to drop out of school because they do not have a good time there...they are not treated equally with the non-Roma children."

In school B, the principal argued again that the problem lies within the Roma parents: "They do not keep basic rules of sanitation...they don't care about their children...they do not enroll them in school because they think that they can survive without education." The principal seemed to believe that the lack of hygiene is an inherent characteristic of the Roma, ignoring the fact that they are usually unemployed and live in camps without access to running water or electricity (ECRI, 2015). She also emphasized the distance between the children's living experience and the school demands. She stated that it is impossible to bridge the communication gap: "It is like I am coming from NASA." She also added that some parents are in jail, while some students come from single-parent families. Roma culture is perceived as inherently anti-schooling. It is widely held that school attention is not part of their system of values" (Zachos, 2012). The principal stressed that "Roma children prefer to be free, to play and dance instead of being in a classroom." Thus, when Roma cultural characteristics are acknowledged to exist, they are seen as either barriers toward the provision of public services or an excuse to allow Roma to exclude themselves from education (Lloyd \& McCluskey, 2008). The principal concluded that "nothing will change; these children will not remain at school." However, she added that even irregular school attendance is important for establishing better conditions in the future.

In this school, none of the sampled students had attended kindergarten. Moreover, none of their parents/legal guardians had attended school. Thus, when children entered primary school, there was no school experience in their families. All students faced great difficulties and had poor achievement. It is characteristic that three out of the four sampled students were siblings of different ages, but they were all attending the third grade. Only one student made a point on the reasons for the high dropout rates of Roma, transferring the responsibility to his peers: "They do not like studying; their parents must exert 
pressure on them." With respect to the parents, the first participant was the mother of three sampled students; she has eight children in total. It is worth noting that three of her children had already dropped out of school. The second participant was the grandmother/legal guardian of the last sampled student. Both parents/legal guardians did not make any clear point as to the reasons for the high dropout rates of Roma. They only stressed the need to get financial aid from the state, while the grandmother stated that Roma students do not have the same opportunities as their non-Roma peers.

\section{School Practices for Empowering Roma Children}

The principal of school A argued that they did their best to encourage school attendance of Roma students by establishing a pleasant pedagogical environment, organizing various events, and running reception classes. However, these initiatives were not enough, as "the problem lies within the Roma and their culture....If the state gave them a daily allowance, they would attend school every day." Simultaneously, he stated vaguely that their cultural identity has to be respected and that they must be included in society without losing their culture. The principal of school B also stated vaguely that school does its best and emphasized that she violates the law by allowing Roma children to remain at school only for some hours, in order to be acquainted with the school environment. Roma cultural identity is once again approached in folklorist terms: "We let them come to school all dressed up, wearing jewellery and makeup, that means acceptance." Both principals appeared to be certain that educational intervention is not enough; this may explain why they underestimated the importance of in-service training.

Both teachers stated that they respect the cultural identity of the Roma and try to make use of it in the classroom. They claimed that they use modern practices to improve the learning process for the benefit of all students, such as individualized and collaborative teaching, role playing, or film projections. The second teacher added that Roma students cannot keep up with the curriculum and some of them face "obvious" learning difficulties, thus medicalizing social issues. He tried to overcome these difficulties by adjusting the teaching material to their educational level. According to Bernstein (1991), when some of the students cannot follow the pace of the curriculum, teachers either loosen up a little bit from the program or they reduce the amount or/and the quality of what they teach. All these practices, however, create a more advanced system of stratified educational practices. We noticed that teachers expressed different views regarding the current attitude of the Roma towards schooling. The first teacher believed that there was an improvement in attendance rates, as well as in the cooperation of Roma parents with the school, while the second one argued that nothing had changed. 


\section{Roma Perceptions of Education and Relations with the Non-Roma School Community}

In school A, six out of the eight students had attended kindergarten. These children stated that they had good relations with their teachers in kindergarten, as well as in primary school. However, two of them added that they experienced physical and verbal abuse by non-Roma children in kindergarten, while one other student socialized only with Roma children. The importance of early school experience clearly emerges, as these three children also mentioned that they had had no relations (or had bad ones) with non-Roma children in primary school. One other child, who had not attended kindergarten, mentioned that she had moderate relations with non-Roma children. In primary school, all students had poor achievement and no desire to attend school regularly, as they were not provided with the cultural capital that the official school demands but does not teach. It should be mentioned that two siblings of our sampled students had already dropped out of school before completing primary education. However, all students expressed the wish to graduate from high school and make their own vocational or academic choices (hairdresser, doctor, teacher, footballer), instead of pursuing their parents' profession.

The father from school A stressed the need for his children to attend school, because his occupation no longer offered safety. Therefore, he believed that "school is the only hope." He expressed his determination to help his children graduate from lower secondary school, but he stated, "It lies on them to decide whether they will continue." He claimed that he meets teachers as often as he can, he participates in school events and he has good relations with teachers and non-Roma parents. The mother stated that kindergarten is important for the transition to primary school; however, three of her children did not attend kindergarten "because of family problems." The academic and professional prospects of her children seem to be predetermined. She said that she wishes her children to acquire basic literacy skills in order to run the family business with better prospects, and she added that she faced many difficulties because she was illiterate. However, one of her sons had already dropped out of school after graduating from primary school, while the second one repeated the first grade of primary school. One of her daughters, along with her nieces, was not attending school regularly. Moreover, she stated that she will not enroll her daughters in secondary school because "we have heard that children smoke and use drugs... primary school is different, it is next to us." Feelings of fear and insecurity for the transition to secondary school, where Roma students will turn into minorities, clearly emerged. She had no contacts with teachers and with nonRoma parents, and she did not participate in school events, thus reproducing long-standing stereotypes. 
In school B, all students mentioned that they had good relations with their teachers but less so with non-Roma children. One student was socializing only with Roma children. One student expressed the will to graduate from high school and become a pilot. Two students wished to stop school after graduating from primary school and work as hairdressers, while the last one wished to graduate from lower secondary school. The mother was totally absent from the school life; however, she argued that school was important for her children "in order to find a job and avoid being like us," and she stated that they did not experience discrimination in school. The grandmother also argued that school was important for children in order to acquire reading and writing skills, although she had no contact with the school community. However, unlike the mother, she stated that Roma did not have the same opportunities with the non-Roma children "who live in better conditions and have permanent residence."

\section{The View of the Mediators and the Coordinator of the Programme}

In many European countries, Roma mediators contribute variously to the educational inclusion of Roma. The role of mediators depends on the country. In Slovakia and Bulgaria, for example, the mediators are members of the Roma community. In Slovakia, they work with families that depend on social aid, while in Bulgaria the role of the mediators is to help children to overcome the language barrier and to improve communication between children, teachers and parents. On the other hand, in France most mediators are not Roma and their role is not clear, as they work in several areas. Among their responsibilities is to encourage Roma parents to enroll their children in school, as well as to participate in negotiations with mayors concerning the establishment of encampments in the municipalities. (Kirilova \& Repaire, 2003). The overall outcomes of the mediators' work are positively assessed, especially in terms of increasing the rates of students' enrollment and graduation from compulsory education (Open Society Institute, 2007). In Greece, there is no provision for hiring mediators in schools. Drawing from the experience of other countries, the Committee of the Programme organized training courses for Roma mediators in 2011. The courses were repeated when there was a need to recruit mediators. Drawing from the experience of other countries, the Committee of the Programme trained Roma adults as mediators. All participants in this research assessed positively the work of mediators in bridging the communication gap between the Roma and the school community and bringing children back to school. Mediators also can compensate for the inadequacies of the official school to ensure the regular attendance of Roma children, a role that, as other studies indicate (Zachos, 2012), school authorities often avoid taking over.

The mediator of school $A$ argues that the high dropout rates of Roma children are due to various reasons, emphasizing their parents' responsibility. 
Some parents claim that their children do not want to attend school...others keep them home to help with the house chores...some mothers are afraid that their girls will elope...parents do not believe in the importance of schooling...there is lack of trust and cooperation with the school...some children work.

However, when she was asked how the dropout rates could be reduced, she emphasized the teachers' role: "Teachers bear the major responsibility...the ways they treat children in order to keep them in class."

The mediator of school B clearly shifted the responsibility for the high dropout rates of Roma at school: "Most students stop attending school because teachers do not pay attention to them...teachers marginalize Roma students...non-Roma students also marginalize Roma students...they prefer not to play with them." Moreover, he argued that the state must provide the Roma families with more financial and psychological support and take action to fill in the communication gap between the Roma and the teachers.

The coordinator of the "City" argued that establishing a school free of stereotypes and discriminatory practices, which will take into account the distance between the Roma culture and the school culture, will take time. School inclusion of the Roma is difficult, as they are not adequately supported by their families, some of them have not attended kindergarten, they lack social skills, and they face the stereotypical views of their teachers. She also stressed that the effectiveness of educational intervention programs depends on whether or not they operate on a permanent basis.

\section{Conclusion}

Principals and teachers tend to shift the entire responsibility for the high dropout rates of Roma students onto the latter's socio-cultural characteristics. They declare their tolerance and positive attitude towards the Roma by lowering demands and expectations and by turning a blind eye to Roma irregular attendance. As Bourdieu (2000) argues, "It is through the incorporation of social structures in the form of dispositional structures, of objectives chances in the form of expectations or anticipations, that we acquire a practical knowledge and control of the encompassing space" (p. 130). That practical knowledge determines teachers' perceptions about what depends on them and what does not; and what is reasonable for them to do, hope, and ask for. Thus, principals and teachers fail to address the role of the social and educational structures in the reproduction of inequalities and indicate that the Roma prefer to be uneducated and live in isolation.

The practices of the self, as Foucault argues, are not self-invented but are based on norms that already exist in a given socio-political and cultural context. 
Thus, most Roma children have been transformed into the illiterate and undisciplined subjects that they are expected to be, in accordance with the dominant norms in the society at large and in their own community, They accept their own or their families' responsibility for their failure to adjust to the school norms. Only three out of the 12 students in the study referred to teachers' responsibility. Roma parents tend not to accept any responsibility and they stress the inadequacies of the welfare state or the negative role of the school. The long experience of discrimination and social exclusion, as ECRI reports in Greece indicate, has established the Roma adults' negative stance towards the dominant "others," even though they personally had not experienced discriminatory practices in the schools of the City. The mediator of school B shared the same view with Roma parents.

Although the results of this research cannot be generalized, the conflicting views of the principals and teachers on the one hand and the parents on the other highlight the deadlock of the current situation. Additionally, Roma children, still being in the socialization process, participate in a blame game that has nothing to offer them. In the current conditions of economic crisis in Greece, there are great difficulties in applying consistent policies for the improvement of the Roma position in school and society. Hence, it is encouraging that the largest increase of Roma attendance rates was achieved during this very period of crisis through the implementation of the Programme for the education of Roma children. The great challenge, now, is to retain the attendance rates of Roma children and to improve their school achievement and life chances. The first priority must be to question the myth of the socially neutral school by organizing intensive in-service training for teachers and principals, providing highly diverse schools with well-experienced and educated teachers, and establishing an inclusive school culture that will allow Roma children and parents to be an active part of school life. However, we certainly do not overlook that, in the long run, building relations of trust between the Roma and the non-Roma members of the school community largely depends on the overturn of the discriminations that the Roma experience in all aspects of Greek social, economic, and cultural life.

\section{References}

Appadurai, A. (2005). Modernity at large. Minnesota, MN: University of Minnesota Press.

Banks, J. A. (2010). Multicultural education: Characteristics and goals. In J. A. Banks \& C. A. McGee Banks (Eds.), Multicultural education ( $7^{\text {th }}$ ed., pp. 330). New Jersey, NJ: Wiley.

Bauman, Z. (1997). Modernity and its discontents. Cambridge, UK: Polity.

Bauman, Z. (2004). Europe: An unfinished adventure. Cambridge, UK: Polity. 


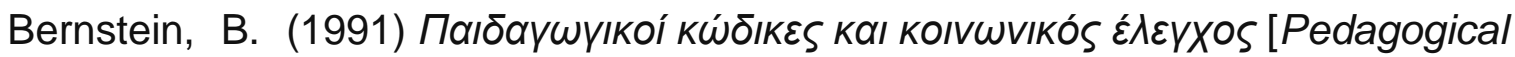
codes and social control]. Athens, GR: Alexandria.

Bourdieu, P. (1990). The logic of practice. Cambridge, UK: Polity.

Bourdieu, P. (2000). Pascalian meditations. Palo Alto, CA: Stanford University Press.

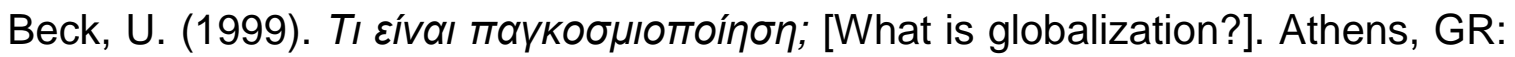
Kastanioti.

Cohen, L., Manion, L., \& Morrison, K. (2005). Research methods in education ( $5^{\text {th }}$ ed.). London, UK: Routledge.

Council of the European Union (2009). Council conclusions on inclusion of the Roma. Retrieved from http://www.consilium.europa.eu/uedocs/cms_data/ docs/pressdata/en/lsa/108377

Coulby, D. (2011). Intercultural education. The theory deficit and the world crisis. In C. A. Grant \& A. Portera (Eds.), Intercultural and multicultural education (pp. 98-109). London, UK: Routledge.

ECRI (2000). Second report on Greece. Strasbourg, FR: Council of Europe.

ECRI (2004). Third report on Greece. Strasbourg, FR: Council of Europe.

ECRI (2009). Fourth report on Greece. Strasbourg, FR: Council of Europe.

ECRI (2015). Fifth report on Greece. Strasbourg, FR: Council of Europe.

Erickson, F. (2010). Culture in society and in educational practices. In J. A. Banks \& C. A. McGee Banks (Eds.), Multicultural Education ( $7^{\text {th }}$ ed., pp. 3356). New Jersey, NJ: Wiley.

European Commission (2004). The situation of Roma in an enlarged European Union. Luxemburg, LU: Office for Official Publications of the European Communities.

Foucault, M. (1978). The history of sexuality, Vol. I: An introduction. New York, NY: Pantheon.

Foucault, M. (1986). The history of sexuality, Vol III: The care of the self. New York, NY: Pantheon.

Gillborn, D. (1995). Racism and antiracism in real schools. Philadelphia, PA: Open University Press.

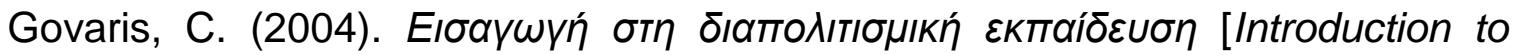
intercultural education]. Athens, GR: Atrapos.

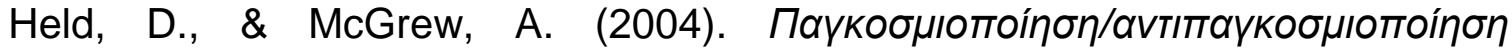
[Globalization/anti-globalization]. Athens, GR: Politropon. 
Kirilova, D., \& Repaire, V. (2003). The innovatory practices in the field of education of Roma children. Council of Europe. Retrieved from http://www.coe.int/t/dg4/education/roma/Source/GoodPractice_EN.PDF

Kontogiannopoulou-Polydorides, G., \& Fragoulis, G. (2009). H бuүкро́тпбn тwV

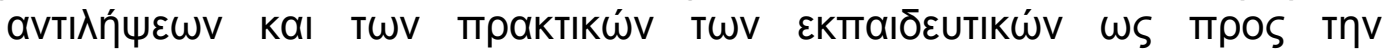

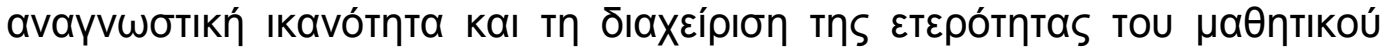

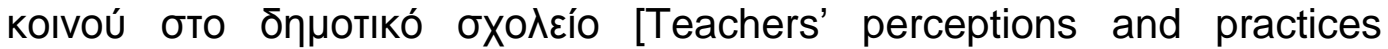
regarding reading literacy of diverse student population in primary school].

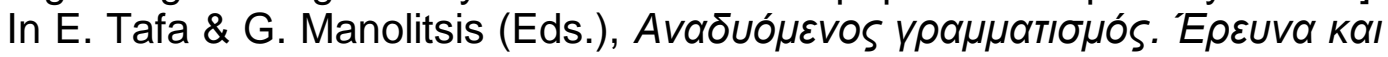
$\varepsilon \varphi \alpha \rho \mu о \gamma \varepsilon ́ s$ [Emerging literacy. Research and applications] (pp 195-204). Athens, GR: Pedio.

Kymlicka, W. (2007). Multicultural odysseys. Oxford, UK: Oxford University Press.

Kymlicka, W. (2015). Solidarity in diverse societies: Beyond neoliberal multiculturalism and welfare chauvinism. Comparative Migration Studies, 3(17), 2-19.

Lareau, A. (2003). Unequal childhoods. Los Angeles, CA: University of California Press.

Lewy, G. (2000). The Nazi persecution of the gypsies. New York, NY: Oxford University Press.

Lloyd, G., \& McCluskey, G. (2008). Education and gypsies/travelers: Contradictions and significant silences. International Journal of Inclusive Education, 12(4), 331-345.

McGrew, A. (2003). A global society? In S. Hall, D. Held, \& A. McGrew (Eds.), Modernity and its futures (pp. 61-116). Cambridge, UK: Polity and Open University.

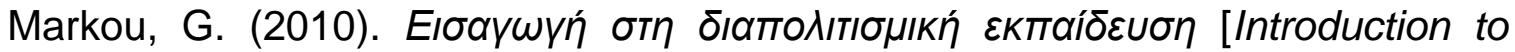
intercultural education]. Athens, GR: University of Athens Publications.

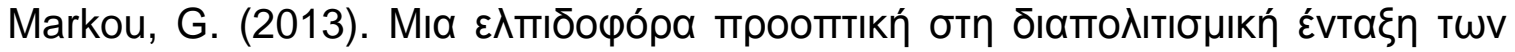

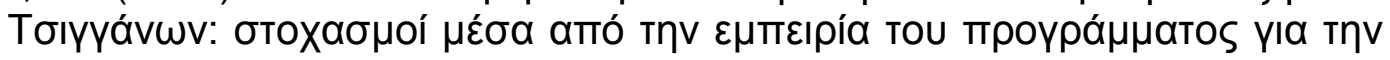

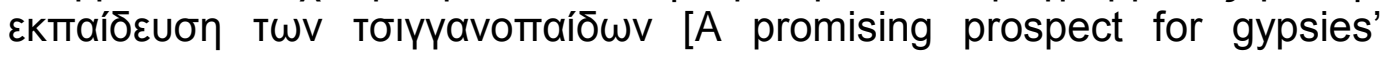
inclusion: Drawing from the experience of the Programme for the education of Roma]. In G. Flouris, L. Gioti, C. Parthenis, \& E. Miligou

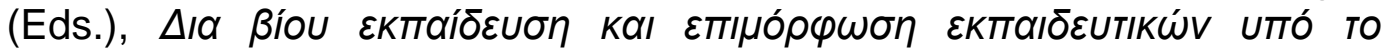

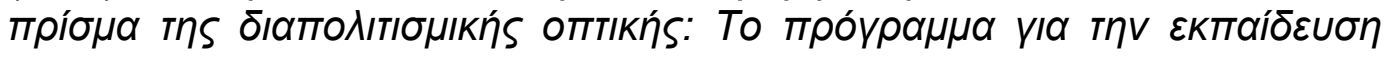

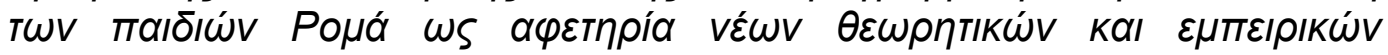

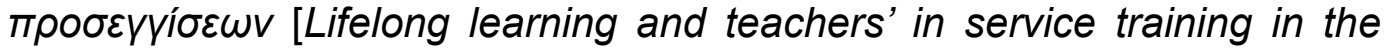
scope of intercultural education: The Programme for the Education of Roma Children as starting point of new theoretical and empirical approaches] (pp. 17-41). Athens, GR: University of Athens Publications. 
May, S. (2009). Critical multiculturalism and education. In J. A. Banks (Ed.), The Routledge international companion to multicultural education (pp. 33-48). New York, NY: Routledge.

Mayring, P. (2004). Qualitative content analysis. In U. Flick, E. Kardorff, \& I. Steinke (Eds.), Companion to qualitative research (pp. 266-269). London, UK: Sage.

McGarry, A. (2010). Who speaks for Roma? New York, NY: Continuum.

Modood, T. (2013). Multiculturalism. Cambridge, MA: Polity.

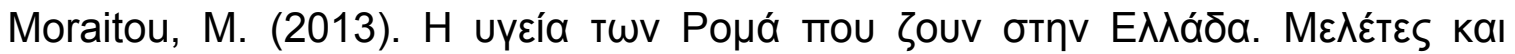
$\varepsilon \varphi а \rho \mu о \gamma \varepsilon ́ s$ [The health of Roma who live in Greece. Studies and

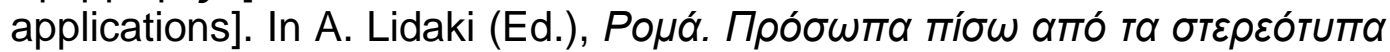
Roma [Faces behind the stereotypes] (pp. 131-150). Athens, GR: Alexandria.

Neuman, W. L. (2014). Social research methods. Harlow, UK: Pearson.

Open Society Institute (2007). Equal access to quality education for Roma, Vol. I. Retrieved from https://www.opensocietyfoundations.org/sites/default/files/ 1summary_20070329_0.pdf

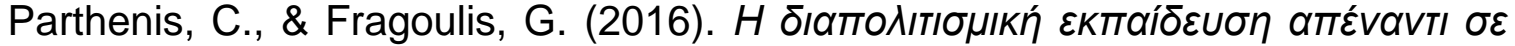

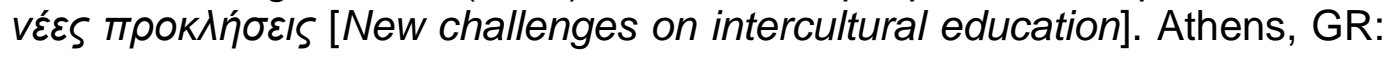
Metaixmio.

Ryan, J. (2003). Leading diverse schools. Dordrecht, NL: Kluwer.

Sayad, A. (2004). The suffering of the immigrant. Cambridge, UK: Polity.

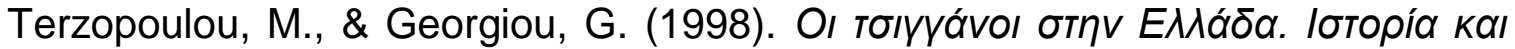
кou入roúpa [Gypsies in Greece. History and culture]. Athens, GR: Ministry of Education.

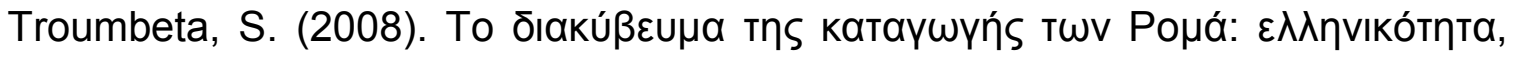

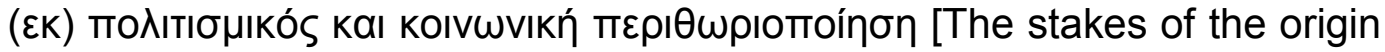
of Roma: Greekness, civilization and marginalization]. In S. Troumbeta

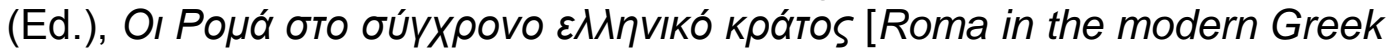
state] (pp. 93-125). Athens, GR: Kritiki.

Vertovec, S., \& Wessendorf, S. (2010). Introduction: Assessing the backlash against multiculturalism in Europe. In S. Vertovec \& S. Wessendorf (Eds.), The multiculturalism backlash (pp. 1-31). London, UK: Routledge.

Widmann, P. (2007). The campaign against the restless: Criminal biology and the stigmatization of the gypsies, 1890-1960. In R. Stauber \& R. Vago (Eds.), The Roma. A minority in Europe (pp. 19-29). Budapest, HU: Central European University Press. 
Zachos, D. (2012). Institutional racism? Roma children, local community and school practices. Journal for Critical Education Policy Studies, 10(2), 5366.

\section{Author Contact}

Christos Parthenis: parthenis@ppp.uoa.gr

National and Kapodistrian University of Athens, Athina, Greece

George Fragoulis: gfragoul@yahoo.gr

National and Kapodistrian University of Athens, Athina, Greece 